\title{
Positive and negative effects of intertidal algal canopies on recruitment and survival of barnacles
}

\author{
George H. Leonard* \\ Brown University, Department of Ecology and Evolutionary Biology, Providence, Rhode Island 02912, USA
}

\begin{abstract}
Understanding the diverse ways that species interact in communities continues to pose significant challenges to experimental ecologists. By simultaneously (1) abrading the substrate (i.e. 'whiplash'), (2) altering local hydrodynamics and abiotic conditions and (3) influencing predator densities, marine algae can alter the recruitment and survival of the organisms with which they co-occur. I used predator exclusion cages and canopy manipulations in the barnacle-algae (Semibalanus balanoides-Ascophyllum nodosum) zone in Rhode Island (USA) intertidal habitats to demonstrate how to experimentally tease apart these types of multiple effects. In the absence of algal abrasion, barnacle recruitment was greater under the algal canopy than in cleared areas. This suggests that the canopy did not reduce the delivery of larvae but, rather, created a depositional environment where larvae accumulated. The overall effect of the canopy, however, was a reduction in recruitment compared to cleared areas because algal whiplash overwhelmed these positive, hydrodynamic effects. Predators had very little effect on the recruitment of barnacles. In contrast to recruitment, I found that the canopy positively influenced the early post-recruitment survival of $S$. balanoides. The reduction in survival caused by predators was offset by an increase in survival caused by both the physical presence of the canopy (probably by reducing thermal stress) and its subsequent mechanical abrasion of the substrate (probably by reducing the accumulation of sediments). For both recruitment and survival, the effects of algal whiplash were twice as large as those of modifying the habitat or influencing predation intensity. In general, my findings illustrate how a series of a priori, statistical comparisons within a multi-factorial experiment can be used to separate and quantify these types of multiple effects in plant-animal interactions.
\end{abstract}

KEY WORDS: Recruitment vs post-recruitment processes - Larval delivery - Algal whiplash - Mechanical abrasion - New England rocky intertidal zone Ascophyllum nodosum Semibalanus balanoides

\section{INTRODUCTION}

A continuing challenge to community ecologists is to understand the diverse ways that species interact in communities. The experimental manipulation of species in their natural habitats has proven to be a remarkably powerful tool with which to do this (Underwood 1997). Understanding the specific mechanisms by which species interact, however, is more problematic, especially if the overall effect of one species on another is the result of several, simultaneous influences. For example, in marine systems, large canopy-

\footnotetext{
- Present address: Stanford University, Department of Biological Sciences, Hopkins Marine Station, Pacific Grove, CA 93950-3094, USA. E-mail: leonardg@leland stanford.edu
}

forming vegetation cannot only influence environmental conditions (e.g. light, temperature, water motion; Fonseca et al. 1982, Lobban \& Harrison 1994) but can also physically interfere with recruiting and established organisms (Grant 1977, Duggins et al. 1990, Grizzle et al. 1996) and indirectly alter predator densities and per capita predation rates (Menge 1978). Simply manipulating the canopy alone provides no information on which of these effects is most important to the ecology of the organisms associated with it. In addition, predicting how the interaction will vary with environmental conditions requires an understanding of the direction, magnitude and importance of the individual effects that contribute to the overall interaction. Only carefully designed and evaluated experimental treatments (e.g. Huston 1997) combined with species manipulations can provide such information. 
In this study, I have used rocky intertidal habitats in New England, USA, to show how to experimentally tease apart these types of multiple effects. Like many aquatic and terrestrial habitats, the intertidal zone of semi-exposed shores in this area is dominated by large, canopy-forming vegetation (i.e. Ascophyllum nodosum and Fucus spp.; Menge 1976, Chapman 1995). The primary space occupier in these habitats is the northern acorn barnacle Semibalanus balanoides (Menge 1976). For many years, ecologists have recognized that the recruitment and survival of barnacles that live under intertidal macroalgal canopies are typically reduced compared to areas where canopies are naturally absent or have been experimentally removed (Connell 1961, Menge 1976, Hawkins 1983). This overall reduction in recruitment and survival may be due to 1 or more processes that are simultaneously influenced by the canopy but the relative contribution of each is not well known (Hunt \& Scheibling 1997).

Specifically, decreased recruitment under canopies may be the result of the algal fronds mechanically interfering with the settlement process. This 'whiplash' effect occurs when waves cause the algae to abrade the substrate and dislodge larvae as they attempt to settle (Lewis 1964, Menge 1976). On the other hand, reduced recruitment may also be the result of how the structure of the algal canopy modifies the local hydrodynamic regime. Hatton (1938) and Southward (1956) hypothesized that, by decreasing flow rates, the canopy would reduce the delivery of planktonic larvae to the benthos. This idea is supported by more recent studies that have found that variation in recruitment at relatively large spatial scales (hundreds of meters to kilometers) can often be explained by variation in the delivery rate (i.e. flux) of larvae that effectively act as passive particles (Hawkins \& Hartnoll 1982, Johnson 1985, Butman 1987, Gaines \& Bertness 1992, Pineda 1994, Wing et al. 1995). On the other hand, relatively small-scale studies (millimeters to centimeters) predict that the decreased velocity, shear stress and turbulence within the canopy should result in a depositional environment where larvae passively accumulate and are then better able to explore settlement sites (Crisp 1955, Eckman 1983, Gallagher et al. 1983, Jumars \& Nowell 1984, Pawlik et al. 1991, Mullineaux \& Garland 1993. Snelgrove \& Butman 1994). It is not clear whether the predictions from large- or small-scale studies best apply to the intermediate spatial scales (meters to tens of meters) at which within-site variation in community structure can be large (e.g. Menge 1976). It is also not clear whether mechanical interference or hydrodynamic modification by the canopy is responsible for reduced recruitment.

Like recruitment, post-recruitment survival under algal canopies has often been shown to be influenced by the vegetation (e.g. Menge 1976). Algal whiplash may interfere with the acquisition of food resources (Palmer et al. 1982) or it may scour from the rock even those individuals that manage to settle and undergo metamorphosis (Grant 1977). Alternatively, by reducing water velocity and shear stress, the canopy may enhance sedimentation and resultant mortality from smothering (Eckman \& Duggins 1991). By harboring predators, the canopy may also indirectly enhance mortality of sessile prey (Menge 1978, Minchinton \& Scheibling 1993a). To complicate matters more, intertidal algal canopies may enhance the overall survival of post-recruitment individuals by reducing desiccation and thermal stress at low tide (Dayton 1971). The relative role of algal whiplash and habitat modification to patterns of survival under algal canopies is far from clear.

The mechanisms by which algal canopies modify patterns of recruitment and post-recruitment survival have been speculated upon since the early work of Hatton (1938), but none of the past studies has partitioned the overall effect of the canopy into its component parts of whiplash, habitat modification and predation pressure (Hunt \& Scheibling 1997). Menge (1976) showed that algal whiplash could decrease recruitment rates but it was unclear what role the effect of water motion had on his results. Using artificial algal fronds, Grant (1977) similarly argued that whiplash reduced post-recruitment survival but how habitat modification by the canopy influenced his findings is not known. In this study, I have used traditional predator exclusion cages and canopy manipulations to partition the overall effect of the Ascophyllum nodosum canopy on the recruitment and survival of Semibalanus balanoides into these component parts.

\section{METHODS AND MATERIALS}

This study was done in the mid to high intertidal zone at 2 open coast rocky shores in Rhode Island (New England) from December 1995 through October 1996. The 2 sites (Sachuest Point Nature Reserve and Sakonnet Point) were located on the western and eastern shores, respectively, of Narragansett Bay. Each site had gently sloping rock benches, interspersed with large boulders that had approximately $50 \%$ cover of barnacles Semibalanus balanoides and were covered at low tide by a continuous layer of the knotted wrack Ascophyllum nodosum. A. nodosum holdfasts covered less than $10 \%$ of the available substrate. Monthly wave forces, measured using spring-loaded dynamometers, ranged from 30 to $40 \mathrm{~N}$ throughout 1996 and indicated that the sites were of intermediate wave exposure (see Leonard in press for further details). 
Unlike sites farther to the north (e.g. Maine, USA, see Menge 1976, Leonard et al. 1998), these sites had comparatively low densities of barnacle predators. Both Nucella lapillus and Carcinus maenus, which can occur at densities over 100 and 1 ind. $\mathrm{m}^{-2}$, respectively, in Maine (Menge 1976, Leonard et al. 1998), were generally rare at these southern sites. $N$. lapillus was absent in the high zone and reached densities of only 1 ind. $\mathrm{m}^{-2}$ in the low intertidal zone (author's unpubl. data). When seen, C. maenus was only present under the $A$, nodosum canopy in the low intertidal zone (author's pers. obs.).

These low densities of predators suggested that consumers played a limited role in governing barnacle recruitment and survival at these southern sites. This scarcity of predators also made it possible to use traditional predator exclusion cages to experimentally separate the positive and negative effects of the Ascophyllum nodosum canopy on Semibalanus balanoides recruitment and survival without the confounding effect of simultaneously altering strong predation effects. By placing cages (both full cages and partial cages) under the canopy, the mechanical abrasion of the algal fronds on the substrate was prohibited while the physical structure of the overlying algal bed was left undisturbed. A series of statistical comparisons within this experimental design (see below) was used to separate the effects of (1) predators, (2) habitat modification by the canopy and (3) algal whiplash on barnacle recruitment and survival.

To do this, an identical experiment was done just below the upper border of the Ascophyllum nodosum zone at each site (Fig. 1). A canopy treatment (plots completely cleared of all macroalgae [radius $=1 \mathrm{~m}$ ] or control plots with $100 \%$ canopy cover of A. nodosum) and a cage treatment (substrate open [O] or covered by a full cage [FC] or a partial cage [PC]) were set out in an orthogonal design in early December 1995. Plots were chosen haphazardly and were separated by $\sim 3 \mathrm{~m}$ along $200 \mathrm{~m}$ of shore. Treatment designations were allocated randomly to all plots. Permanent quadrats $(\mathrm{n}=8 ; 20 \times 20 \mathrm{~cm})$ within each of these treatment combinations were marked at their corners with galvanized bolts drilled into the rock surface. All quadrats were nestled amongst the $A$. nodosum holdfasts and initially had approximately $50 \%$ cover of barnacles. Full cages and partial cages $(20 \times 20 \times 5 \mathrm{~cm})$ were made of galvanized wire mesh (mesh size $=0.5 \times 0.5 \mathrm{~cm}$ ) . Partial cages were identical to full cages except that 2 of the 4 sides had $15 \times 2.5 \mathrm{~cm}$ openings to allow mobile organisms to enter the cage. All cages were attached flush to the rock surface in the center of the permanent quadrat with a single galvanized bolt through the center of the cage. Cages that were damaged during the experiment were replaced.

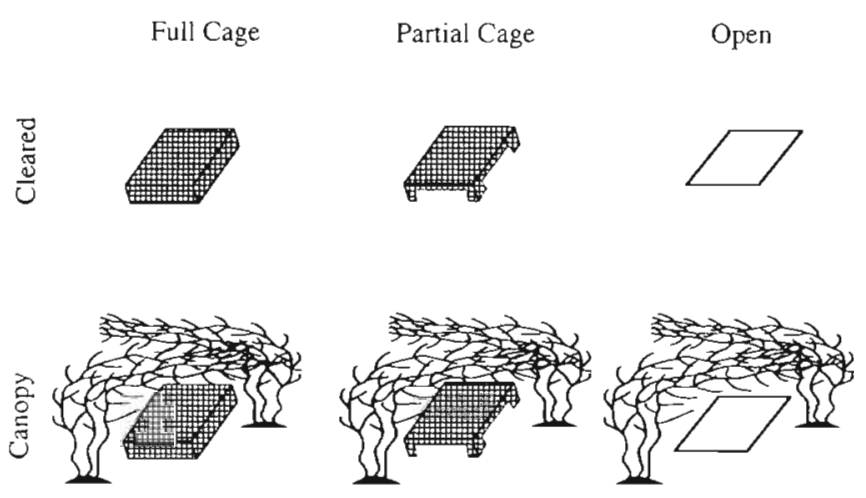

Fig. 1. Experimental design to partition and quantify the positive and negative effects of the intertidal Ascophyllum nodosum canopy on Semibalanus balanoides recruitment and post-recruitment survival. This design was employed at 2 open coast sites in Narragansett Bay, Rhode Island, USA. Squares represent the permanent quadrats on the rock substrate

All quadrats were cleared to bare rock with a paint scraper and wire brush in late December 1995 and barnacle recruitment into the quadrats was monitored periodically during the following spring. To reduce edge effects, counts were made in the central $225 \mathrm{~cm}^{2}$ of each quadrat. When barnacle settlement had ceased (March 1996), densities were sampled a final time and this value was used as a measure of recruitment. The density of barnacles was also quantified periodically over the course of the summer and when thermal stress had abated in October, barnacle survival (density in October divided by density in March) was calculated for each quadrat.

The net effect of the algal canopy on barnacle recruitment and post-recruitment survival was analyzed with a mixed-model analysis of variance (ANOVA) using site, canopy treatment and cage treatment as factors. Canopy treatment and cage treatment were considered fixed factors while site was considered a random factor. Recruitment was $\sqrt{\boldsymbol{x}+1}$ transformed and survival was arcsine $\sqrt{x}$ transformed to reduce variance heteroscedasticity and enhance normality. The components of the analysis of greatest interest were the 'canopy $\times$ cage $\times$ site' interaction and the 'canopy $\times$ cage' interaction. The former tested whether the influence of the canopy and cage treatments was consistent between sites. If their influence did not vary between sites, the 'canopy $\times$ cage' treatment was evaluated. If the 'canopy $\times$ cage' interaction was significant, I used a series of planned comparisons (a priori contrasts in SuperAnova ${ }^{\text {MM }}$ vers. 1.11, Abacus Concepts, Inc.) to evaluate the relative contribution of algae-mediated predation, habitat modification and whiplash to patterns of barnacle recruitment and mortality. 
Contrast 1-Cage structure artifact: 'cleared, FC/PC vs cleared, $\mathrm{O}^{\prime}$. Contrast 1 was a control to test whether full cages and partial cages could be used to separate the mechanical effects of the algal canopy (i.e. whiplash) from their influence on the physical habitat in which Semibalanus balanoides lived. The ideal test would have been a partial cage that had the structure of a full cage but also allowed the algae to abrade the substrate. As it was physically impossible to build this type of cage, the following comparative approach was taken.

If recruitment or survival in full cages and partial cages (in cleared plots) was similar to that in open quadrats (in cleared plots), I concluded that there was little evidence that the physical structure of the cage itself altered patterns of recruitment or survival. Cages could then simply be used to separate the effects of whiplash from those of habitat modification in the canopy plots. Alternatively, the physical structure of the cage itself may have increased or decreased barnacle recruitment or survival. If it did, Contrast 1 quantified this cage artifact and it was then subtracted from Contrast 4 (see below). This approach assumes that the effect of cages under the algal canopy was the same as that in cleared plots (i.e. the response was additive) and that the effect was linear across this range of canopy cover (i.e. there was no threshold response).

Contrast 2-Predator effect: (1) 'cleared, PC vs cleared, FC' and (2) 'canopy, PC vs canopy, FC'. Contrast 2 was an explicit test of the hypothesis that predators played a minor role in governing the recruitment and survival of Semibalanus balanoides at these sites. Comparisons were made separately for cleared and canopy plots because predator effects have often been found to vary among habitats (e.g. Menge 1978). I concluded that predators reduced recruitment or survival if these measures were significantly greater in full cages than in partial cages in either habitat.

Contrast 3 - Test of algae-mediated habitat modification: 'canopy, FC/PC vs cleared, FC/PC'. Because cages prevented algal whiplash but did not disturb the structure of the algal canopy, Contrast 3 was used to evaluate the consequences of algal-mediated habitat modification on the recruitment and survival of Semibalanus balanoides. Assuming early post-settlement mortality was similar in the presence or absence of algae, the canopy may have (1) reduced delivery of larvae to the substrate through decreased water flow (canopy, FC/PC < cleared, FC/PC) or (2) created a depositional environment where larvae accumulated (canopy, FC/PC > cleared, FC/PC). For recruitment, these alternative depositional scenarios may be due to a combination of the canopy acting on larvae as passive particles and the potential differential behavior of larvae in response to treatment manipulations. The rel- ative role of passive versus active settlement is difficult to tease apart in the field and could not be quantified in this experiment. Nonetheless, the difference between the 'cleared, FC/PC' and 'Canopy, FC/PC' treatments was an overall measure of the magnitude of habitat modification by algae on patterns of recruitment.

Contrast 3 also provided a measure of how habitat modification altered patterns of post-recruitment survival. By reducing water flow, the canopy might have (1) decreased the delivery of suspended food resulting in higher mortality or (2) increased siltation and mortality by smothering. Alternatively, a reduction of desiccation and thermal stress by the overlying canopy at low tide might overwhelm these negative effects and result in increased post-recruitment survival.

Contrast 4-Test of mechanical interference (whiplash): 'canopy, O vs canopy, FC/PC'. Contrast 4 compared the effect of caging in the presence of the canopy and thus evaluated the strength and magnitude of algal whiplash on the recruitment and survival of barnacles. If Contrast 4 was significant, I concluded that direct contact with the algal fronds (1) influenced the settlement process or early post-settlement mortality and/or (2) altered the survival of post-recruitment juveniles. For each variable, the difference between the treatments was a measure of the magnitude of these effects. If Contrast 1 was also significant, the magnitude of this cage artifact was subtracted from Contrast 4 to yield the true effect of whiplash. As before, this approach assumes additivity in the cage response and no threshold effect for cages under the algal canopy. Using this series of contrasts, the net effect of Ascophyllum nodosum on the recruitment and survival of Semibalanus balanoides was partitioned into its 3 component parts.

\section{RESULTS}

\section{Barnacle recruitment}

The magnitude of barnacle recruitment and the effect of the experimental treatments did not vary between sites (Table 1). However, there was an overall interaction between the canopy and cage treatments on barnacle recruitment (Table 1). Recruitment in plots cleared of the canopy was significantly greater under full and partial cages than in open quadrats (Fig. 2, Table 2, Contrast 1), indicating that the physical structure of the cage itself elevated recruitment compared to open quadrats. In contrast, there was no difference in recruitment between full cages and partial cages in either cleared plots or canopy plots (Table 2, Contrast $2.1,2.2$ ), indicating that predators had little influence on barnacle recruitment at these sites during 1996. 
Table 1. Results of the 3-way ANOVA on barnacle recruitment. Factors were site, canopy treatment and cage treatment. Data were $\sqrt{x+1}$ transformed before analysis. Significant $p$-values are given in bold for clarity. Error terms for the $F$-ratio are indicated in the right-hand column: a, Residual $;$ b, Canopy $\times$ Site; c Cage $\times$ Site; $d$, Canopy $\times$ Cage $\times$ Site

\begin{tabular}{|lrrrc|}
\hline Source of variation & df & MS & $F$ & p \\
\hline Site & 1 & 52.90 & 2.64 & $0.108 \mathrm{a}$ \\
Canopy & 1 & 4.34 & 0.33 & $0.669 \mathrm{~b}$ \\
Cage & 2 & 382.18 & 103.34 & $\mathbf{0 . 0 1 0} \mathrm{C}$ \\
Canopy $\times$ Site & 1 & 13.26 & 0.66 & $0.419 \mathrm{a}$ \\
Cage $\times$ Site & 2 & 3.70 & 0.18 & $0.832 \mathrm{a}$ \\
Canopy $\times$ Cage & 2 & 87.46 & 20.58 & $\mathbf{0 . 0 4 6} \mathrm{d}$ \\
Canopy $\times$ Cage $\times$ Site & 2 & 4.25 & 0.21 & $0.810 \mathrm{a}$ \\
Residual & 84 & 20.06 & & \\
\hline
\end{tabular}

Within cages, recruitment was significantly greater under the canopy than in cleared plots (Fig. 2, Table 2, Contrast 3). Under the canopy, recruitment into open quadrats was significantly lower than into cages (Fig. 2, Table 2, Contrast 4). These data indicate that, in the absence of whiplash, recruitment was enhanced by the presence of the canopy (Contrast 3). However, when fronds were allowed to abrade the substrate, recruitment was reduced beyond that explained by the cage artifact alone (Contrast 4 ).

The relative strength of the cage artifact was similar to that of the habitat modification effect but the predator effect was very small (i.e. 0.2 to 0.3 , Table 2 ). In contrast, the relative strength of the whiplash effect was

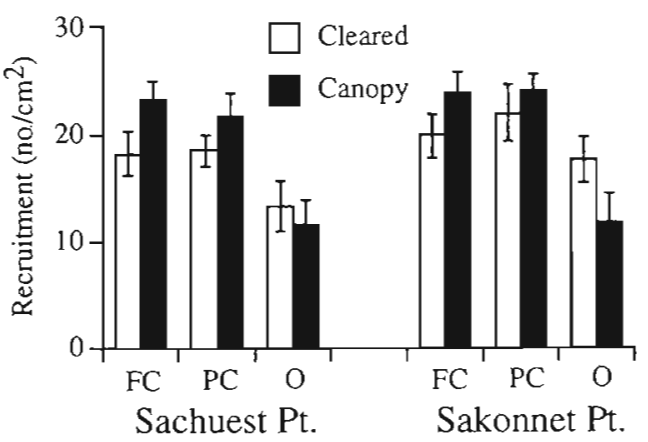

Fig. 2. Barnacle recruitment in May 1996 as a function of the canopy and cage treatments at the 2 study sites. See Table 1 for statistical analysis. Data are means $\pm 1 \mathrm{SE}$. The 4 planned comparisons are presented in Table 2 and, for clarity, are not shown here. FC: full cage, PC: partial cage, O: open

over 2 times greater than the habitat modification effect (i.e. 2.1, Table 2). The net result of these 3 simultaneous processes was an overall reduction in recruitment of Semibalanus balanoides by the Ascophyllum nodosum canopy of nearly $25 \%$ compared to nearby cleared plots.

\section{Post-recruitment survival}

Like recruitment, the effects of the canopy and cage treatments on barnacle survival did not vary between sites, but the 'canopy $\times$ cage' interaction was statistically significant (Fig. 3, Table 3). In plots cleared of

Table 2. Planned comparisons (contrasts) from the ANOVAs on barnacle recruitment and survival. $F$-values (significant values in bold) for each contrast are shown. Degrees of freedom for all contrasts were 1,2. Magnitude: absolute size of the effect calculated as the difference in the first treatment mean from the second treatment mean. (Units are ind. $\mathrm{m}^{-2}$ for recruitment and \% for survival). Arrows indicate whether recruitment or survival of the first treatment mean was increased ( $\Uparrow$ ) or decreased $(\downarrow)$ relative to the second treatment mean. Relative strength: magnitude of an effect compared to the algal-mediated habitat modification effect. It was calculated as the magnitude of the contrast divided by the magnitude of Contrast 3

\begin{tabular}{|c|c|c|c|c|c|c|c|c|c|c|}
\hline \multirow[t]{2}{*}{ Contrast } & \multicolumn{5}{|c|}{ Recruitment } & \multicolumn{5}{|c|}{ Survival } \\
\hline & $F$ & $\mathrm{p}$ & & Magnitude & $\begin{array}{l}\text { Relative } \\
\text { strength }\end{array}$ & $F$ & $\mathrm{p}$ & & Magnitude & $\begin{array}{l}\text { Relative } \\
\text { strength }\end{array}$ \\
\hline \multicolumn{11}{|l|}{ Cage structure artifact } \\
\hline 1. Cleared, FC/PC vs Cleared, O & 25.32 & 0.037 & $\Uparrow$ & 4.2 & 1.2 & 0.18 & 0.716 & - & 0.0 & 0.0 \\
\hline \multicolumn{11}{|l|}{ Predator effect } \\
\hline 2.1. Cleared, PC vs Cleared, FC & 1.15 & 0.396 & $\Downarrow$ & 1.2 & 0.3 & 0.04 & 0.865 & $\Downarrow$ & 1.0 & 0.1 \\
\hline 2.2. Canopy, PC vs Canopy, FC & 0.48 & 0.560 & $\Uparrow$ & 0.7 & 0.2 & 17.35 & 0.053 & $\Downarrow$ & 5.4 & 0.8 \\
\hline \multicolumn{11}{|l|}{ Algae-mediated habitat modification } \\
\hline 3. Canopy, FC/PC vs Cleared, FC/PC & 19.88 & 0.047 & $\Uparrow$ & 3.6 & 1.0 & 40.78 & 0.024 & $\Uparrow$ & $6.7^{\mathrm{b}}$ & 1.0 \\
\hline \multicolumn{11}{|c|}{ Test of mechanical interference (whiplash) } \\
\hline 4. Canopy, O vs Canopy, FC/PC & 194.10 & 0.005 & $\Downarrow$ & $7.4^{\mathrm{d}}$ & $2.1^{\mathrm{d}}$ & 80.22 & 0.012 & $\Uparrow$ & $14.5^{c}$ & 2.2 \\
\hline
\end{tabular}


algae, barnacle survival under full cages and partial cages was similar to that in open quadrats (Fig. 3, Table 2, Contrast 1), indicating that the physical structure of the cage itself had no effect on survival. In cleared plots, there was also no difference in survival between full cages and partial cages (Table 2, Contrast 2.1) but, in canopy plots, there was a marginally significant increase in survival in full cages compared to partial cages (Table 2, Contrast 2.2). This suggests that barnacle survival was reduced by predators under the canopy but not in cleared plots.

In the presence of full cages, Semibalanus balanoides survival was significantly greater under the canopy than in cleared plots (Fig. 3, Table 2, Contrast 3). When algal fronds were allowed to abrade the substrate, barnacle survival was further elevated beyond that in the full cages and partial cages (Fig. 3, Table 2, Contrast 4).

The relative strength of the predator effect on barnacle survival under the canopy was similar to that of the habitat modification effect (i.e. 0.8, Table 2) but was very low in cleared plots (i.e. 0.1, Table 2). In contrast, the relative strength of the whiplash effect was 2.2 times greater than that of the habitat modification effect (Table 2). The net result of these 3 processes ( 2 positive and 1 negative) was an increase in survival of Semibalanus balanoides by the Ascophyllum nodosum canopy of over $360 \%$ compared to nearby cleared plots.

\section{DISCUSSION}

\section{Positive and negative effects of Ascophyllum nodosum canopies on Semibalanus balanoides recruitment}

My results illustrate that intertidal Ascophyllum nodosum canopies at the 2 study sites decreased Semibalanus balanoides recruitment but increased post-

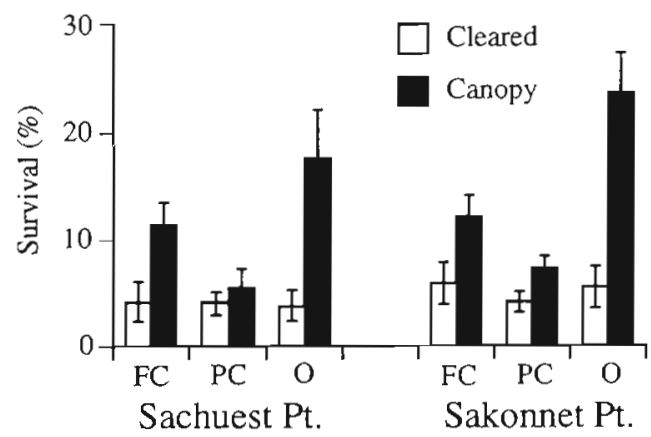

Fig. 3. Barnacle survival in October 1996 as a function of the canopy and cage treatments at the 2 study sites. Data are means $\pm 1 \mathrm{SE}$. See Table 3 for statistical analysis. The 4 planned comparisons are presented in Table 2 and, for clarity, are not shown here. $\mathrm{FC}$ : full cage, PC: partial cage, $\mathrm{O}$ : open
Table 3. Results of the 3-way ANOVA on barnacle survival. Factors were site, canopy treatment and cage treatment. Data were arcsine $\sqrt{x}$ transformed before analysis. Significant p-values are given in bold for clarity. Error terms for the $F$-ratio are indicated in the right-hand column: a, Residual; b. Canopy $\times$ Site; $c$, Cage $\times$ Site; $d$, Canopy $\times$ Cage $\times$ Site.

Four cages that were lost were excluded from the analysis

\begin{tabular}{|lrrrr|}
\hline Source of variation & df & MS & \multicolumn{1}{c}{$F$} & $\mathrm{p}$ \\
\hline Site & 1 & 0.047 & 3.78 & $0.055 \mathrm{a}$ \\
Canopy & 1 & 0.622 & 3007.05 & $\mathbf{0 . 0 1 2} \mathrm{b}$ \\
Cage & 2 & 0.082 & 18.87 & $\mathbf{0 . 0 5 0} \mathrm{C}$ \\
Canopy $\times$ Site & 1 & $<0.001$ & 0.02 & $0.898 \mathrm{a}$ \\
Cage $\times$ Site & 2 & 0.004 & 0.35 & $0.707 \mathrm{a}$ \\
Canopy $\times$ Cage & 2 & 0.098 & 22.83 & $\mathbf{0 . 0 4 2} \mathrm{d}$ \\
Canopy $\times$ Cage $\times$ Site & 2 & 0.004 & 0.35 & $0.708 \mathrm{a}$ \\
Residual & 80 & 0.012 & & \\
& & & & \\
\hline
\end{tabular}

recruitment survival. These net effects were the result of several processes operating simultaneously. The mechanism by which the $A$. nodosum canopy inhibited $S$. balanoides recruitment was mechanical abrasion of the substrate (i.e. algal whiplash) rather than a reduction in larval delivery. As expected, I found no evidence that predators influenced the early recruitment success of $S$. balanoides (Table 2). My findings are thus consistent with those of Lewis (1964), Menge (1976) and Grant (1977), who argued that direct interference by algae was responsible for reduced barnacle recruitment. In contrast, I found no evidence consistent with the hypothesis that reduced water flow within the canopy decreased barnacle recruitment through a reduction in larval input. In fact, the physical structure of the canopy itself appeared to create a depositional environment where larvae accumulated in the absence of direct interference by the algal fronds. My results are thus inconsistent with the hypothesis of Hatton (1938), Southward (1956) and Connell (1961), who argued for the importance of a canopy-mediated reduction in larval delivery to the substrate. These results suggest that the frequent observation of lower recruitment under large canopy-forming seaweeds at sites of intermediate wave exposure may not be a consequence of how algal canopies alter local hydrodynamics but rather a mechanical consequence of the fronds abrading the substrate.

These conclusions do not take into consideration the importance of larval behavior and early post-settlement mortality to the patterns of recruitment I measured in the field. Instead of passively accumulating under the canopy, larvae may have actively chosen the wetter habitats there, as has been suggested to occur with ephemeral algae (Strathmann \& Branscomb 1979, Minchinton \& Scheibling 1993a), or actively avoided the cleared habitats because of high light (Pyefinch 
1948 ) or low abundance of certain microalgae that may act as settlement cues (LeTourneux \& Bourget 1988). Early post-settlement mortality may also have contributed substantially to the patterns of recruitment that I measured. Early mortality can be exceedingly high in barnacles (Gosselin \& Qian 1996) and to be quantified recruits need to be sampled on time scales much shorter than those used here (see Minchinton \& Scheibling 1993b). Thermal stress is not important in New England in March, but the algal canopy may have reduced desiccation stress and thus reduced the mortality of cyprids and recent metamorphs. During field sampling, however, I never observed large numbers of dehydrated cyprids and metamorphs (indicative of impending mortality from water loss) in cleared plots. This suggests that early post-settlement mortality did not vary greatly between habitats. Caution is warranted, however, because an unquantified amount of the 'deposition' result may have been due to habitatspecific mortality of recently settled barnacles.

Regardless of the relative contribution of passive larval delivery, active larval behavior and early postsettlement mortality to the patterns of recruitment that I measured, these processes were much less important than were the mechanical effects of algal abrasion. The reduction in recruitment due to algal whiplash was over twice as large as the increase in recruitment due to factors affecting deposition. Although algal canopies certainly modify local hydrodynamics, it appears to be their mechanical effects that are most important to patterns of recruitment in Semibalanus balanoides. These types of mechanical effects of algal canopies have also been argued to be important in the reduction of recruitment, growth and survival of solitary and colonial corals in tropical habitats (Tanner 1995).

\section{Positive and negative effects of Ascophyllum nodosum canopies on Semibalanus balanoides survival}

In contrast to recruitment, I found evidence of a positive influence of the canopy on barnacle survival during the first 6 mo after recruitment. This was despite a reduction in survival under the canopy caused by predators (likely the green crab Carcinus maenus; Ropes 1968, Leonard et al. in press). The overall increase in survival under the canopy was due to both habitat modification and algal whiplash. By modifying the flow regime, the structure of the canopy may have increased the deposition of food particles and reduced metabolic stress. Its most important effect, however, was likely the reduction of the severe thermal stress that is common during the summer in these southern intertidal habitats (Wethey 1984, Leonard in press)
The second positive effect of the canopy was direct mechanical abrasion. Whiplashing by the algal fronds increased Semibalanus balanoides survival relative to quadrats protected from abrasion by cages. My study thus does not support the notion that algal whiplash increases juvenile mortality as proposed by Grant (1977). Like seagrass and kelp beds in subtidal habitats (Eckman \& Duggins 1991, Leonard \& Luther 1995), intertidal canopies may create environments in which sedimentation is elevated. In my experiment, sweeping of the substrate by Ascophyllum nodosum fronds may have resuspended these sediments and elevated barnacle survival compared to caged quadrats where the resuspension of these sediments was reduced. At shores with greater wave exposure than those used in my study, algal canopies likely reduce post-recruitment survival by severely abrading the substrate, especially if species composition changes to shorter, tougher plants in these habitats (Stephenson \& Stephenson 1948, Dayton 1971, Hawkins 1983). Whether canopies enhance sediment resuspension (and elevate survival) or severely scour the substrate (and reduce survival) will depend critically on wave exposure.

\section{Cage artifacts, statistical assumptions and the utility of a comparative approach}

In this experiment, traditional predator exclusion cages were capable of teasing apart the multiple effects of the algal canopy on barnacle recruitment and survival. Careful consideration of cage artifacts (e.g. Steele 1996) and statistical assumptions, however, is required to ensure validity of the results. For example, in cleared plots, the presence of both full cages and partial cages increased barnacle recruitment compared to open quadrats (Contrast 1). This indicated that the physical structure of the cage itself increased recruitment. The magnitude of this potential bias was subtracted from Contrast 4 to yield the true magnitude of the whiplash effect. No evidence of a cage artifact was detected for barnacle survival, so similar data manipulations were not required.

In addition to careful attention to cage artifacts, this comparative approach requires that the influence of the full cages and partial cages in cleared plots be similar to those in canopy plots. This implies that the cage effect is additive among the different algal treatments and that the response varies linearly with the amount of algal canopy cover. The strength of my conclusions is dependent on the validity of this assumption. However, a careful test of it must await a controlled flume experiment on how cage structures influence hydrodynamic conditions, larval settlement and patterns of 
recruitment across a wide range of canopy cover and plant density.

Many species have multiple, simultaneous effects on the other species with whom they are interacting. Predicting interactions across a range of abiotic and biotic conditions will require knowledge of the magnitude and direction of the individual processes that combine to influence the overall interaction. The approach used here, a series of specific statistical contrasts within a multi-factorial experimental design, can separate and quantify these types of multiple effects. For example, my approach quantified the relative influence of predators, habitat modification and algal whiplash to patterns of Semibalanus balanoides recruitment and survival. Manipulations of the algal canopy alone could not provide this information because all these processes are simultaneously modified by the canopy.

\section{Spatial scale of hydrodynamic processes}

My study may provide some insight into the spatial scales at which hydrodynamic processes influence recruitment in marine systems. Studies at large spatial scales have stressed that within- and among-site variation in recruitment can often be explained by variation in the flux of passively dispersed larvae (e.g. Johnson 1985, Gaines \& Bertness 1993, Pineda 1994). These results conflict with studies done at small spatial scales that show recruitment is often inversely proportional to flux (Crisp 1955, Eckman 1983, Mullineaux \& Garland 1993, Breitburg et al. 1995). The reasons these studies reach opposite conclusions may largely relate to the spatial scale and biological context in which recruitment occurs.

Recruitment rates may largely be explained by the flux of larvae when considering a species that recruits into bare patches or into areas where interactions with other members of the community are minimal. In these cases, differences in water movement may explain most of the variance in recruitment density. When a species recruits into partly occupied patches or into established communities (as in my study), variation in recruitment may largely be governed by depositional processes coupled with any direct mechanical effects of established community members. Similarly, variation in survival is determined by how the established community (1) modifies the habitat, (2) alters interactions with predators and (3) physically interacts with the organisms that manage to successfully recruit to these communities. In my study in intertidal habitats, the magnitude and importance of these mechanical effects (i.e. whiplash) were greater than those of habitat modification or predation intensity.
These findings certainly do not imply that habitat modification or predation intensity are always overshadowed by physical interactions with established community members. They do suggest that the challenge to ecologists is to better comprehend the multiple ways in which species interact. This includes an improved understanding of the spatial scales at which larval flux and larval behavior interact with the local community and the resultant consequences for organism survival. Incorporating a comparative approach, like that used here, from small to large spatial scales would contribute to this goal.

Acknowledgements. This study could not have been done without the hard work of many members of the Bertness Lab at Brown University. M. Baker and A. Ingraham, in particular, diligently drilled holes into hard granite rock to set up this experiment only days before the birth of my son, Douglas. T. H. Leonard steadfastly supported me during this work and for this I owe many words of thanks. M. D. Bertness provided intellectual and logistical support throughout this project. The study was funded, in part, by grants from Sigma $\mathrm{Xi}$ and The Sounds Conservancy to G.H.L. and from the National Science Foundation and the Mellon Foundation to M. D. Bertness, Earlier versions of the manuscript were greatly improved by comments from K. Earls, P. Ewanchuk, T. Rand, J. Bruno, T Minchinton, R. Karlson and 4 anonymous reviewers.

\section{LITERATURE CITED}

Breitburg DL, Palmer MA, Loher T (1995) Larval distributions and the spatial patterns of settlement of an oyster reef fish: responses to flow and structure. Mar Ecol Prog Ser 125: $45-60$

Butman CA (1987) Larval settlement of soft-sediment invertebrates: the spatial scales of pattern explained by active habitat selection and the emerging role of hydrodynamical processes. Oceanogr Mar Biol Annu Rev 25: $113-165$

Chapman ARO (1995) Functional ecology of fucoid algae: twenty-three years of progress. Phycologia 34:1-32

Connell JH (1961) The influence of interspecific competition and other factors on the distribution of the barnacle Chthamalus stellatus. Ecology 42:710-723

Crisp DJ (1955) The behavior of barnacle cyprids in relation to water movement over a surface. J Exp Biol 32:569-590

Dayton PK (1971) Competition, disturbance, and community organization: the provision and subsequent utilization of space in a rocky intertidal community. Ecol Monogr 41 : $351-389$

Duggins DO, Eckman JE, Sewell AT (1990) Ecology of understory kelp environments. II. Effects of kelps on recruitment of benthic invertebrates. J Exp Mar Biol Ecol 143:27-45

Eckman JE (1983) Hydrodynamic processes affecting benthic recruitment. Limnol Oceanogr 28:241-257

Eckman JE, Duggins DO (1991) Life and death beneath macrophyte canopies: effects of understory kelps on growth rates and survival of marine, benthic suspension feeders. Oecologia 87:473-487

Fonseca MS, Fisher JS, Zieman JC, Thayer GW (1982) Influence of the seagrass, Zostera marina L., on current flow. Estuar Coast Shelf Sci 15:351-364 
Gaines SD, Bertness MD (1992) Dispersal of juveniles and variable recruitment in sessile marine species. Nature 360 : $579-580$

Gaines SD, Bertness MD (1993) The dynamics of juvenile dispersal: why field ecologists must integrate. Ecology 74 : $2430-2435$

Gallagher ED, Jumars PA, Trueblood DD (1983) Facilitation of soft-bottom benthic succession by tube builders. Ecology 64:1200-1216

Gosselin LA, Qian PY (1996) Early post-settlement mortality of an intertidal barnacle: a critical period for survival. Mar Ecol Prog Ser 135:69-75

Grant WS (1977) High intertidal community structure on a rocky headland in Maine, USA. Mar Biol 44:15-25

Grizzle RE, Short FT, Newell CR, Hoven H, Kindblom L (1996) Hydrodynamically induced synchronous waving of seagrasses: 'monami' and its possible effects on larval mussel settlement. J Exp Mar Biol Ecol 206:165-177

Hatton $H$ (1938) Essais de bionomie explicative sur quelques especes intercotidales d'algues et d'animaux. Annls Inst Oceanogr, Monaco 17:241-348

Hawkins SJ (1983) Interactions of Patella and macroalgae with settling Semibalanus balanoides (L.). J Exp Mar Biol Ecol 71:55-72

Hawkins SJ, Hartnoll RG (1982) Settlement patterns of Semibalanus balanoides (L.) in the Isle of Man (1977-1981). J Exp Mar Biol Ecol 62:271-283

Hunt HL, Scheibling RE (1997) Role of early post-settlement mortality in recruitment of benthic marine invertebrates. Mar Ecol Prog Ser 155:269-301

Huston MA (1997) Hidden treatments in ecological experiments: re-evaluating the ecosystem function of biodiversity. Oecologia 110:449-460

Johnson DR (1985) Wind-forced dispersion of blue crab larvae in the Middle Atlantic Bight. Cont Shelf Res 4:1-14

Jumars PA, Nowell ARM (1984) Fluid and sediment dynamic effects on marine benthic community structure. Am Zool $24: 45-55$

Le Tourneux F, Bourget $E$ (1988) Importance of physical and biological settlement cues used at different spatial scales by the larvae of Semibalanus balanoides. Mar Biol 97 : $57-66$

Leonard GH (in press) Latitudinal variation in species interactions: a test in the New England rocky intertidal zone. Ecology

Leonard GH, Levine JM, Schmidt PR, Bertness MD (1998) Flow-driven variation in community structure in a Maine estuary. Ecology 79:1395-1411

Leonard GH, Ewanchuk PJ, Bertness MD (in press) How recruitment, intraspecific interactions and predation control species borders in a tidal estuary. Oecologia

Leonard LA, Luther ME (1995) Flow hydrodynamics in tidal marsh canopies. Limnol Oceanogr 40:1474-1484

Lewis JR (1964) The ecology of rocky shores. English University Press, Ltd, London

Lobban CS, Harrison PJ (1994) Seaweed ecology and physiology. Cambridge University Press, Cambridge

Menge BA (1976) Organization of the New England rocky

Editorial responsibility: Ronald Karlson (Contributing Editor), Newark, Delaware, USA intertidal community: role of predation, competition, and environmental heterogeneity. Ecol Monogr 46:355-393

Menge BA (1978) Predation intensity in a rocky intertidal community: effect of an algal canopy, wave action and desiccation on predator feeding rates. Oecologia 34:17-35

Minchinton TE, Scheibling RE (1993a) Free space availability and larval substratum selection as determinants of barnacle population structure in a developing rocky intertidal community. Mar Ecol Prog Ser 95:233-244

Minchinton TE, Scheibling RE (1993b) Variations in sampling procedure and frequency affect estimates of recruitment in barnacles. Mar Ecol Prog Ser 99:83-88

Mullineaux LS, Garland ED (1993) Larval recruitment in response to manipulated field flows. Mar Biol 116:667-683

Palmer AR, Szymanska J, Thomas L (1982) Prolonged withdrawal: a possible predator evasion behavior in Balanus glandula (Crustacea: Cirripedia). Mar Biol 67:51-55

Pawlik JR, Butman CA, Starczak VR (1991) Hydrodynamic facilitation of gregarious settlement of a reef-building tube worm. Science 251:421-424

Pineda J (1994) Internal tidal bores in the nearshore: warm water fronts, seaward gravity currents and the onshore transport of larvae. J Mar Res 52:427-458

Pyefinch KA (1948) Notes on the biology of cirripedes. J Mar Biol Assoc UK 27:464-503

Ropes JW (1968) The feeding habits of the green crab, Carcinus maenas (L.). US Fish Wildl Serv Fish Bull 67:183-203

Snelgrove PVR, Butman CA (1994) Animal-sediment relationships revisited: cause versus effect. Oceanogr Mar Biol Annu Rev 32:111-177

Southward AJ (1956) The population balance between limpets and seaweeds on wave-beaten rocky shores. Rep Mar Biol Stn Pt Erin 68:20-29

Steele MA (1996) Effects of predators on a reef fishes: separating cage artifacts from effects of predtion. J Exp Mar Biol Ecol 198:249-267

Stephenson TA, Stephenson A (1948) The universal features of zonation between tide-marks on rocky coasts. J Ecol 37 : 289-305

Strathmann RR, Branscomb ES (1979) Adequacy of cues of favorable sites used by settling larvae of two intertidal barnacles. In: Stancyk SE (ed) Reproductive ecology of marine invertebrates. University of South Carolina, Columbia, p 77-89

Tanner JE (1995) Competition between scleractinian corals and macroalgae: an experimental investigation of coral growth, survival and reproduction. J Exp Mar Biol Ecol $190: 151-168$

Underwood AJ (1997) Experiments in ecology. Their logical design and interpretation using analysis of variance. Cambridge University Press, Cambridge

Wethey DS (1984) Sun and shade mediate competition in the barnacles Chthamalus and Semibalanus: a field experiment. Biol Bull 167:176-185

Wing SR, Botsford LW, Largier JL, Morgan LE (1995) Spatial structure of relaxation events and crab settlement in the northern California upwelling system. Mar Ecol Prog Ser 128:199-211

Submitted: July 29, 1998; Accepted: November 26, 1998 Proofs received from author(s): March 9, 1999 